Objective Vestibular assessment:- Electronystagmography showed central vestibular abnormalities in 18 (14.5\%), 66 had normal vestibular function and 41 had vestibular hypofunction. Seventeen had bilateral vestibular failure.

Implications and relevance of results In children, numerous aetiologies of dizziness and balance problems may have a similar clinical picture. The symptoms of non-vestibular disorders can masquerade those of vestibular disorders and vice-versa. Close multispecialty working is vital for positive clinical outcome.

\section{PS-349 TELL ME HOW YOU SLEEP: SLEEP HABITS AND DISTURBANCES IN PORTUGUESE PRE-SCHOLAR AND SCHOLAR CHILDREN}

S Lopes, F Almeida, S Jacob, M Figueiredo, C Vieira, F Carvalho. Pediatrics, Centro Hospitalar Do Médio Ave E. P. E., Vila Nova de Famalicão, Portugal

\subsection{6/archdischild-2014-307384.648}

Background and aims Given the risk of significant medical and behavioural morbidity, it is crucial to evaluate sleep disorders in clinical practice. We aimed to evaluate sleep habits and disturbances in pre-scholar and scholar children from a Northern region of Portugal and compare the results with other studies.

Methods Children's Sleep Habits Questionnaire Portuguese version (CSHQ-PT) was applied to parents of healthy children (410 years old) attending daycare centres and elementary schools in our city.

Results 107 pre-scholar and 122 scholar children were included $(n=229)$, mean age 6,3 years. 54,1\% were boys. Prevalence of co-sleeping was 37,3\%. Mean bedtime was 9:41 pm and mean wake-up time was 7:20 am. Mean sleep duration was $9.7 \mathrm{~h}$, being longer in pre-scholars $(p<0.001) .75,7 \%$ of children suffered from global sleep disturbances and the mean CSHQ-PT total score was 47,05 , being higher in pre-scholars $(\mathrm{p}=0,001)$. Pre-scholars also scored higher on bedtime resistance $(\mathrm{p}<$ $0,001)$, sleep onset delay $(\mathrm{p}=0,046)$ and night wakening $(\mathrm{p}<$ $0,001)$. Bedtime resistance and sleep anxiety scores were higher in only children $(\mathrm{p}=0.003)$. The prevalence of enuresis was $7,7 \%$, restless sleep 52,7\% and bruxism 22,2\%. Pre-scholars scored higher in night terrors $(p=0,04)$. It was hard to get the children out of bed in $56.7 \%$ and the children seemed tired during the day in $22.9 \%$.

Conclusion Included children tend to fall asleep later and sleep less than in other studies. A high prevalence of sleep disturbances was found, specially in pre-scholar children, which claims a different approach of this subject in our clinical practice.

\section{PS-350 WITHDRAWN}

\section{PS-351 A GROWING PAINS (GP) QUESTIONNAIRE : VALIDATION AND RELIABILITY CONTROL}

${ }^{1} \mathrm{M}$ Vasilopoulou, ${ }^{2} \mathrm{E}$ Kritseli, ${ }^{2} \mathrm{~N}$ Myriokefalitakis, ${ }^{2} \mathrm{M}$ Tsolia. ${ }^{2}$ 2nd Pediatric Clinic/PICU Penteli'sChildren Hospital, University of Athens Medical School, Athens, Greece; ${ }^{2} 2 n d$ Pediatric Clinic and a Kyriakou Children's Hospital, University of Athens Medical School, Athens, Greece

\subsection{6/archdischild-2014-307384.649}

Background Growing pains (GP) is a common cause for visiting the paediatrician. Their prevalence remains obscure and a screening questionnaire is not available.
Aim To develop a questionnaire, appropriate for the estimation of GP prevalence in the general children's population aged 4-7 years old.

Material and methods After review of the literature, a 27-closed type questions with two-answer options (yes-no) questionnaire was developed, including the parameters of localization, duration, intensity and heredity of growing pains. Content validity and test-retest have been examined in a pilot study preceding the present study. The validity of the questionnaire was further studied in a parental population of children aged 4-7 years old, sourced from a randomly selected elementary school in Athens. The reliability was examined by repeated parents response over 3 weeks.

Results 83 questionnaires were filled out. The final version of the questionnaire comprised 21 questions. The mean test-retest reliability was $75.4 \%$, ranging from $0.33-100 \%$ ( $\mathrm{p}<0.001$, Cronbach alpha coefficient was equal to 0.68 for total scale, ranging from $0.62-0.82$ for the subscales). Construct validity evaluation defined 9 fields incorporating the 21 questions. After excluding low reliability questions, nine items remained in the scale. A cut-off point of $\geq 8$ was finally proposed for the detection and diagnosis of growing pains.

Conclusions We report the development of a reliable and valid questionnaire for GP based on the existing publications. This questionnaire focused on the domains of pain localization, intensity of growing pains and their $24 \mathrm{~h}$ temporal distribution.

\section{PS-352 CHARACTERISTICS OF U. S. CHILDREN WHOSE PARENTS REPORT THEY NO LONGER HAVE AUTISM SPECTRUM DISORDER (ASD)}

${ }^{1} \mathrm{G}$ Montes, ${ }^{2} \mathrm{JS}$ Halterman. ${ }^{1}$ Ralph C. Wilson Jr. School of Education, St. John Fisher College/Children's Institute Inc., Rochester, USA; ${ }^{2}$ Department of Pediatrics, University of Rochester, Rochester, USA

\subsection{6/archdischild-2014-307384.650}

Background/aims Our objective was to determine the characteristics of children who do not retain an autism diagnosis.

Methods The National Survey of Children's Health 2007, a nationally representative survey, asked parents whether a doctor or other health professional had ever told them their child had ASD. Thirty eight percent of those who responded affirmatively also reported that the child did not have ASD currently. We inspect the differences between the ASD-now and no-longer-

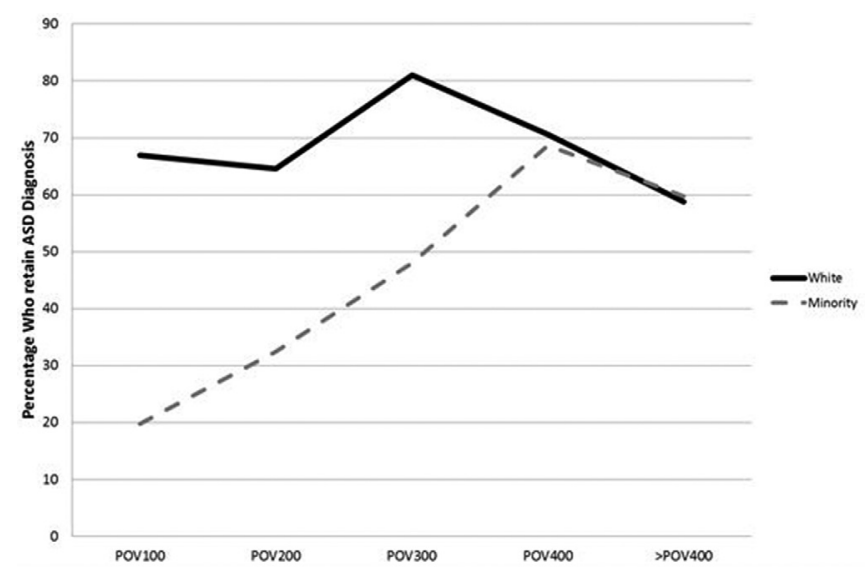

Abstract PS-352 Figure 1 Percentage of children who retain ASD diagnosis by income level and race 
ASD groups using design-corrected F tests and multivariate logistic analyses.

Results Compared with the ASD-now group, the no-longer-ASD group was more likely to be minority (40.6 vs. $18.3 \%$, p < $0.01)$, have parents with high school education or lower (45.6 vs. $28.3 \%, \mathrm{p}<0.05)$, and less likely to be of Hispanic ethnicity (8.0 vs $18.5 \%, \mathrm{p}<0.05)$. The no-longer ASD group was more likely to have had hearing problems (although not currently) (21 vs $10.5 \%, \mathrm{p}<0.05)$, and less likely to have had epilepsy and seizures $(6.2$ vs $13.1 \%, \mathrm{p}<0.05)$, developmental delays (55.6 vs $72.8 \%, \mathrm{p}<0.05$ ) or learning disabilities (56.6 vs $80.3 \%$, p < 0.01 ). Retaining the ASD diagnosis dramatically increased with income levels among minority children, while declining for the most affluent children.

Conclusions In a nationally representative US sample, we found evidence that the groups most likely to be told they have ASD when they do not are minority, low-income children, particularly those with hearing problems.

\section{Primary Care General I}

\section{PS-352a CHILDREN'S RIGHTS IN PRIMARY PAEDIATRIC CARE: EUROPEAN STUDY}

${ }^{1}$ L Martin-Alvarez, ${ }^{2} \mathrm{P}$ Altorjai, ${ }^{3} \mathrm{Z}$ Kovacs, ${ }^{4} \mathrm{M}$ Katz. ${ }^{1}$ Research, AEPap (Asociación Española Pediatría Atención Primaria) ISSOP (International Society for Social Paediatrics and Child Health), Madrid, Spain; ${ }^{2}$ Research, Association of Hungarian Primary Care Paediatricians ECPCP (European Confederation of Primary Care Paediatricians ECPCP (European Confederation of Primary Care Paediatricians), Budapest, Hungary; ${ }^{3}$ Research, Association of Hungarian Primary Care Paediatricians ECPCP (European Confederation of Primary Care Paediatricians, Budapest, Hungary; ${ }^{4}$ Research, IAPA (Israel Ambulatory Pediatric Association) ISSOP (International Society for Social Paediatrics and Child Health), Tel-Aviv, Israel

\subsection{6/archdischild-2014-307384.651}

Background and aims UN Convention on the Rights of the Child (UNCRC) is an essential part of child health promoting policies. Several studies were carried out on the implementation of UNCRC in secondary and tertiary health care levels but not in primary paediatric care (PPC) settings.

PPC model heterogeneity in Europe is related to socioeconomic/demographic factors, paediatric education/training and child health care policies. PPC is either provided by paediatricians or family doctors/GPs. The study aim was to assess under a social paediatrics perspective UNCRC knowledge/implementation in European PPC settings.

Methods As to profile UNCRC in PPC, a questionnaire (Q1) was designed including 23 specific questions regarding rights of protection, provision and participation. The questionnaire was launched as a "monkey survey" to individual paediatricians practicing in PPC settings through the Council of PPC European national societies participating in the study. Specific country data (Excel table) and total merge data were analysed using SPSS tool.

Results 1342 responses received from 10 participating European PPC societies:

-Not enough knowledge: 52\%-71\%.

-Implementation Partly implemented 30\%-67\%, fully implemented 33-66\%

-Equal access to health care: Provided 84\%-99,5\%

-Right to information: Available 90\%.

Conclusions The knowledge/implementation of UNCRC in PPC varies significantly among European countries. Deep gaps on
UNCRC knowledge were found. Equal access to health care is provided in urban areas. UNCRC should be included in paediatric education as well as addressed in PPC planning policies. Further research on UNCRC.

\section{Primary Care General II}

\section{PS-353 COVERAGE OF ANTENATAL APPOINTMENT OF PREGNANT WOMEN ADMITTED TO THE MATERNITY TEACHING HOSPITAL ALCIDES CARNEIRO, PETRÓPOLIS, RIO DE JANEIRO, RJ, BRAZIL}

${ }^{1}$ A Veiga, ${ }^{1} \mathrm{~N}$ Moliterno, ${ }^{2} \mathrm{~A}$ Dutra, ${ }^{1} \mathrm{E}$ Veiga, ${ }^{1} \mathrm{~F}$ Moliterno, ${ }^{3} \mathrm{I}$ Cordebel, ${ }^{1} \mathrm{~A}$ Goncalves, ${ }^{1} \mathrm{P}$ Montagni, ${ }^{4} \mathrm{M}$ Silva, ${ }^{4} \mathrm{R}$ Rezende, ${ }^{4} \mathrm{~V}$ Ferreira, ${ }^{4} \mathrm{~F}$ Guimaraes. ${ }^{1}$ Pediatria, Faculdade de Medicina de Petrópolis, Petrópolis, Brazil; ${ }^{2}$ Pediatria, Universidade Federal Fluminense, Petrópolis, Brazil; ${ }^{3}$ Residente Pediatria, Faculdade de Medicina de Petrópolis, Petrópolis, Brazil; ${ }^{4}$ Graduação Em Medicina, Faculdade de Medicina de Petrópolis, Petrópolis, Brazil

\subsection{6/archdischild-2014-307384.652}

Introduction The Brazil is encouraging actions and campaigns to ensure prenatal care quality to all pregnant women. Recognising the importance of public health policies, it is necessary to know the consequences of these actions on pregnant women in our maternity hospital, which are exclusive to users of the Public Health System.

Objective To quantitatively identify the coverage of antenatal consultations among pregnant women admitted to the maternity HEAC, according to technical guidelines of the Ministry of Health

Method A descriptive, cross-sectional study was conducted between $01 / 08 / 2013$ to $31 / 01 / 2014$. Through a structured questionnaire and review of medical records.

Results We studied 1061 pregnant women, these feature: mean age $24.98 \pm 6.47$ years; $9.1 \pm 2.9$ years of education; $69.4 \%$ live with a partner; and $40.26 \%$ paid work. Concerning the adequacy of prenatal care, we found: Missing: 0.38\%; inappropriate: $8.09 \%$; Intermediate: $12.14 \%$; and appropriate: $75.72 \%$. Totaling $24.28 \%$ of queries considered inadequate. The mean gestational age of entry into prenatal care was $14.8 \pm 7.1$ weeks among all pregnant women. Stratifying pregnant in teenagers and adults, we observed an average of $15.8 \pm 7.4$ ticket and $14.55 \pm 7.02$ weeks, respectively, with statistical significance $(p$ value 0.02 ).

Conclusion Although prenatal be available in the public health of the city, there is still a considerable number of women with absence or inadequate realisation of prenatal care. In addition to observing a delayed uptake, especially among pregnant adolescents. Strategies must be implemented for early identification of pregnant women, resulting in positive effects for children, women and society.

\section{PS-354 ASSISTED REPRODUCTION AND SOMATIC MORBIDITY IN CHILDHOOD - A SYSTEMATIC REVIEW}

${ }^{1}$ LO Kettner, ${ }^{1} \mathrm{~TB}$ Henriksen, ${ }^{2} \mathrm{~B}$ Bay, ${ }^{2} \mathrm{CH}$ Ramlau-Hansen, ${ }^{3}$ US Kesmodel. ${ }^{1}$ Perinatal Epidemiology Research Unit Department of Paediatrics, Aarhus University Hospital, Aarhus N, Denmark; ${ }^{2}$ Department of Public Health Section for Epidemiology, Aarhus University, Aarhus, Denmark; ${ }^{3}$ The Fertility Clinic, Aarhus University Hospital, Aarhus N, Denmark

10.1136/archdischild-2014-307384.653 